
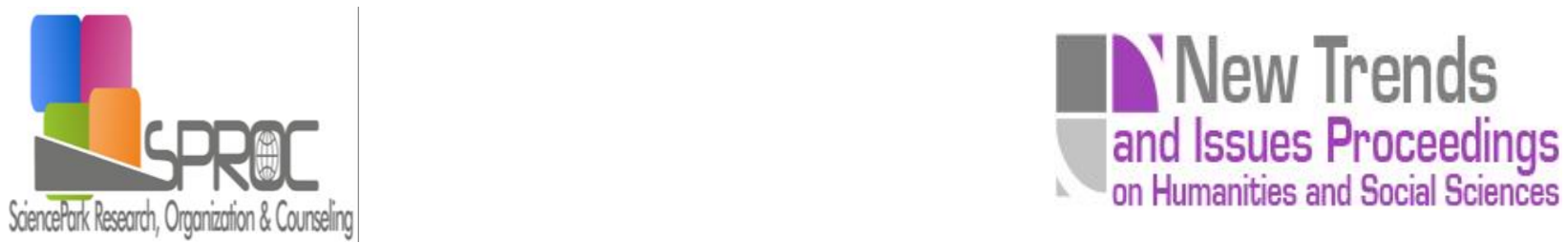

\title{
Analysis of professional ethics in Engineering Degrees
}

Marian Queiruga-Dios *

Juan Jose Bullon-Perez

A. Hernandez Encinas

Suggested Citation:

$e$ rends and ss es Pro eed $n$ son an tes and $o$ a en es

Abstract

Araceli, Queiruga-Dios

a address 
1. Introduction 
2. Practice in ethics education 


\subsection{Curriculum of the Bachelor's Degree}




\section{Conclusions}




\section{Acknowledgements}

\section{References}

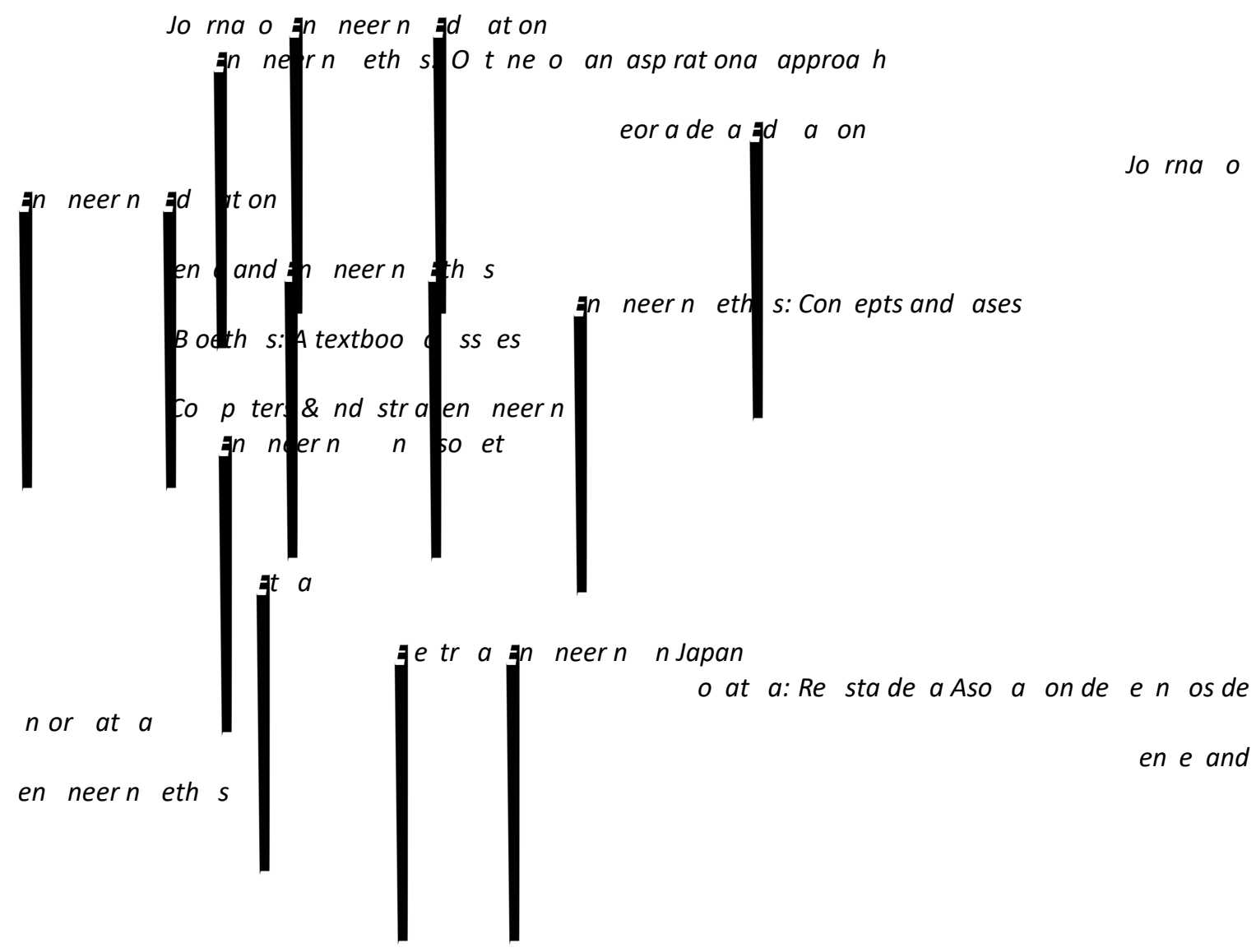

